\title{
Steering SMEs in Nigeria through Recession
}

\author{
Madza, Mark Aondona ${ }^{1}$ Akpera, Dinah Mngushir ${ }^{2}$ \\ 1.Department of Accounting, College of Social and Management Sciences, University of Mkar, Mkar \\ Pmb 017, Gboko Benue State, Nigeria \\ 2.Department of Business Management, College of Social and Management Sciences, University of Mkar, Mkar
}

\begin{abstract}
There is growing concern about the general decline in economic activities in Nigeria. This is evident in the negative Gross Domestic Product (GDP) recorded within the last four quarters of the Nigerian economy. The Central Bank of Nigeria (CBN) and the International Monetary Fund (IMF) confirms that Nigeria is in a period of economic recession. Generally, the economy is made vibrant through aggregate performance of the Small and Medium Enterprises (SMEs). Using a sample of manufacturing SMEs in Nigeria, data and relevant information elicited from selected respondents in SMEs were analyzed using regression and correlation. Findings revealed that there exists a significant relationship between performance of SMEs and recession and that SMEs are affected at different stages of business growth. Empirical works on the subject matter do not explicitly show how SMEs could be managed during recession. To fill this gap, this study therefore adopts the Greiner's model of business growth to establish the different stages of growth and the application of strategies such as: reexamination of structures, policies and procedures, formation of business clusters, value chain management among others that entrepreneurs, consumers and government alike can employ in steering SMEs at various stages during recession period to improve performance.
\end{abstract}

Keywords: Recession, SMEs, Strategies, Entrepreneur

DOI: $10.7176 / \mathrm{EJBM} / 13-14-06$

Publication date:July $31^{\text {st }} 2021$

\section{Introduction}

In a mixed economy like Nigeria, the success of Small and Medium Enterprises (SMEs) depends to a large extent on government economic policies and implementation. Favourable economic policies form the back bone of SMEs growth and sustainability within the economy. They are avenues for job creation and empowerment of Nigeria's citizens providing about $50 \%$ of all jobs in Nigeria and also for local capital formation. Being highly innovative, they lead to the utilization of our natural resources which in turn translates to increasing the country's wealth through higher productivity. SMEs have undoubtedly improved the standard of living of so many people especially those in the rural areas (Ariyo, 2005).

The Central Bank of Nigeria (CBN)'s enabling law (CBN Act 2007) saddles it with the responsibility of the regulation of the country's stock of money in such a way as to promote social welfare. This role is anchored on the use of monetary policy with the primary goal of maintaining stable prices and low inflation rate. Some government policies such as: establishment of the Nigerian Industrial Development Bank (NIDB) and the Nigeria Bank for Commerce and Industry (NBCI), National Directorate of Employment (NDE), Small and Medium Enterprises Equity Investment Scheme (SMEEIS), Bank of Agriculture (BOA) which emerged from the Nigerian Agricultural, Cooperative and Rural Development Bank (NACRDB) and the CBN Anchor Farmer Borrowers Scheme are all aimed at boosting the performance of SMEs.

However, when the economic policies are harsh or unfavourable, the economy suffers thus affecting SMEs growth. For instance the governments' Foreign Exchange (Monitoring and Miscellaneous Provisions) Act of 1995, and the Central Bank of Nigeria (CBN) cash policies on foreign exchange both contributed to the nation's economic down turn. This has affected the growth and performance of SMEs at different stages. This paper seeks to identify the effect of economic recession on SMEs at different stages of growth and the proffer strategies that could be used in steering them through the recession period.

\subsection{Background to the Study}

Globally, increased economic indices of countries are recorded mainly through the activities of SMEs. Hardly do you find any developed country without the proliferation of such. It is primarily through the creation, growth, advancement as well as development of Small and Medium Enterprises (SMEs) that the larger economies of the world such as USA, China, and India have attained their current status of economic development. In such countries, SMEs consist of over 98 per cent of the entire businesses and play a part in more than 65 per cent of employment opportunities (Deen, 2003).

In UK for instance, Small businesses accounted for $99.3 \%$ of all private sector businesses at the start of 2016 and 99.9\% were small or medium-sized (SMEs). Total employment in SMEs was 15.7 million; $60 \%$ of all private sector employment in the country. The combined annual turnover of SMEs was $£ 1.8$ trillion, $47 \%$ of all 
private sector turnover in the UK (fsb.org.uk).

As Nigeria moves towards developing her economy, much emphasis is laid on the growth of the SMEs sector. The institutionalization of policies as mentioned above are all aimed at jumpstarting the economy through improved performance of SMEs. Nevertheless, a negative Gross Domestic Product (GDP) has been recorded within last four quarters of 2016 indicating that Nigeria is in a recession period.

The National Statistics Bureau (NBS) reported that the second quarter 2016 Gross Domestic Product (GDP) declined by -2.06 per cent. Annual inflation rose to 17.1 percent in July from 16.5 percent in June, and food inflation rose to 15.8 percent from 15.3. "The pace of the increase in the headline index was however weighed upon by a slower increase in three divisions, namely health, transport, and recreation and culture divisions," (NBS report, 2016).

According to the statistics agency, the onset of the harvest season was yet to significantly impact on food prices, with food sub-index rising by 15.8 per cent (year-on-year basis) in July, about 0.5 per cent points lower from rates recorded the previous month. Equally, the agency said energy prices accounted for the rise in inflation for the month, with energy and energy related prices recording some of the largest increases reflected in the core sub-index. In July, the core sub-index increased by $16.9 \%$ during the month, up by $0.7 \%$ points from rates recorded in June $(16.2 \%)$. During the month, the highest increases were seen in the electricity, liquid fuel (kerosene), solid fuels, and fuels and lubricants for personal transport equipment' groups.

Within the period under study, the operations of SMEs in Nigeria have been adversely affected. Price hikes in the cost of raw materials, electricity, transportation, increase in exchange rate as well as the devaluation of the Naira, multiple taxation policies and so on constituted a stumbling block to effective performance of SMEs.

\subsubsection{Problem Statement}

Nigeria wishes to be listed among the developed countries like US, UK, China and so on. The government has therefore employed strategies to actualize a vibrant economy by the institutionalization of policies such as: establishment of the Nigerian Industrial Development Bank (NIDB) and the Nigeria Bank for Commerce and Industry (NBCI), National Directorate of Employment (NDE), Small and Medium Enterprises Equity Investment Scheme (SMEEIS), Bank of Agriculture (BOA) which emerged from the Nigerian Agricultural, Cooperative and Rural Development Bank (NACRDB) and the CBN Anchor Farmer Borrowers Scheme.

However, in the course of pursuing her set goals, the government realized that the economy was into recession. Countries that have formulated and implemented policies to develop SMEs record increase in GDP. This is a reverse in the case of Nigeria. Despite the policies formulated and implemented by the government, the aggregate performance of SMEs has not contributed to growth in GDP. Rather than recording increase in GDP, the economy has indicated a negative growth in consistently over the past four quarters of 2016. Could it be that the policies have not been duly implemented? Or they are not sound and appropriate $a b$ initio? Could the issue of multiple taxation be a stumbling block to SMEs performance? Or does the management of SMEs themselves constitute a problem? Or does it mean the accessibility of the available funds by SMEs is another nightmare?

The presence of SMEs in the Nigerian economy and the formulation as well as implementation of policies by the government to encourage SMEs performance has not added the required positive growth in GDP. This constitutes the problem that the researchers hope to unveil.

1.1.2 Study Objectives

The study seeks to:

i. Establish whether there exist a significant relationship between performance of SMEs and Recession.

ii. Determine whether the performance of SMEs is affected at different stages of business growth during recession.

iii. Articulate strategies that could be used in steering SMEs through recession.

1.1.3 Research Questions

In order to determine how SMEs can be steered through recession in Nigeria, the following questions have been postulated.

a. Does any significant relationship exist between performance of SMEs and Recession?

b. Does recession affect the performance of SMEs at different stages of business growth?

c. Are there strategies that could be used in steering SMEs through recession?

1.1.4 Research Hypotheses

$\mathrm{H}_{\mathrm{o} 1} \quad$ There exist no significant relationship between performance of SMEs and Recession

$\mathrm{H}_{\mathrm{o} 2} \quad$ Recession does not affect the performance of SMEs at different stages of business growth

\subsection{Review of Related Literature}

1.2.1 Conceptual Framework

Small and Medium Enterprises (SMEs)

Small and Medium Enterprises (SMEs) can be defined based on certain criteria including, turnover, number of employees, profit, capital employed, available finance, market share and relative size within the industry. The 
definition can be based on either some quantitative or qualitative variables. Quantitative definitions express the size of enterprises mainly in monetary terms such as turnover, asset value, profit, as well as quantitative index like number of employees. For instance, the 1975 companies Act in the United Kingdom stated that an enterprise with a turnover of less than $£ 1.4$ million was small, those with turnover between $£ 1.4$ and $£ 5$.7million were medium, while those enterprises having turnover above $£ 5.7$ million were large. It also went further to classify the enterprises based on number of employees - those with fewer than 50 workers being small, between 50 and 250 workers being medium and those employing above 250 workers were described as being large. Similarly, the European Union (EU) in 1995, defined SME as any enterprise employing less than 250 employees, and went further to break down the SME into micro (less than 10 employees, small from 10 to 49 employees and medium between 50 to 249 employees (Etuk, Etuk and Baghebo, 2014).

In Nigeria, The Central Bank of Nigeria, in its 2005 guideline on Small and Medium Enterprise Investment Scheme (SMEIS), described SME as any enterprise with a maximum asset base of 500million naira (excluding land and working capital) with no lower or upper limit of staff. (CBN, 2005)

On the other hand, the National Council of Industry, categorized enterprises based on three criteria as follows:

Micro/cottage: An enterprise with a labour force not more than 10 workers or a total cost of not more than N1.5 million (including working capital but excluding cost of land).

Small scale: An enterprise with a labour size of $11-100$ workers or a total cost not more than N50million (including working capital but excluding cost of land).

Medium scale: An enterprise with a labour size of 101 - 300 workers or a total cost of over N50million but not more than N200million (including working capital but excluding cost of land). (Madza, M. A, Akpera D. M and Ikeme A. I, 2016)

The national policy on MSMEs has also adopted a definition classification based on the above criteria with a slight deviation on employment. It upheld that, where there is a conflict on classification between assets and employment, the employment based classification will take precedence (National MSME Collaborative Survey, 2013)

Micro Enterprises - are those enterprises whose total assets (excluding land and buildings) are less than Five Million Naira with a workforce not exceeding ten employees.

Small Enterprises - are those enterprises whose total assets (excluding land and building) are above Five Million Naira but not exceeding Fifty Million Naira with a total workforce of above ten, but not exceeding forty-nine employees.

Medium Enterprises - are those enterprises with total assets excluding land and building) are above Fifty Million Naira, but not exceeding Five Hundred Million Naira with a total workforce of between 50 and 199 employees.

For the purpose of this study, the definition by the National Council of Industries as cited above shall be employed.

Recession

Recession is a business cycle contraction, and it refers to a general slowdown in economic activity for two consecutive quarters. During recession, there is usually a decline in certain macroeconomic indicators such as GDP, employment, investment spending, capacity utilization, household income, business income, and inflation, with the attendant increase in the rate of unemployment. Technically, when an economy recorded two consecutive quarters of negative growth in real GDP, it can be said to be in recession. GDP is the market value of all legitimately recognized final goods and services produced in the country in a given period of time, usually one year. According to the African Development bank report, Inflation rose to $12.8 \%$ in 2020 from $11.4 \%$ in 2019 , fueled by higher food prices due to constraints on domestic supplies and the effects of a varying exchange rate premium that widened to about $24 \%$. The removal of fuel subsidies and an increase in electricity tariffs added further to inflationary pressures. The Central Bank of Nigeria cut the policy rate by 100 basis points to $11.5 \%$ to shore up a flagging economy. The fiscal deficit, financed mostly by domestic and foreign borrowing, widened to $5.2 \%$ in 2020 from $4.3 \%$ in 2019, reflecting pandemic-related spending pressures and revenue shortfalls. Total public debt stood at $\$ 85.9$ billion (25\% of GDP) on 30 June $2020,2.4 \%$ higher than a year earlier. Domestic debt represented $63 \%$ of total debt, and external debt, 37\%. High debt service payments, estimated at more than half of federally collected revenues, pose a major fiscal risk to Nigeria. Similarly, the IMF had in an earlier reported that Nigeria's GDP growth contracted to -0.36 per cent in the first quarter of year (Q1 2016) compared to 2.11 per cent in Q4 of 2015 and 3.86 per cent in Q1 2015. Also, the country's Consumer Price Index (CPI), which measures inflation, rose by 0.9 per cent to an 11 -year high of 16.5 per cent. A typical business cycle, as demonstrated in Figure 1 has a period of booms (prosperity), followed by a period of recession, slump and recovery. During the boom period, there is minimal unemployment; high production and consumption; high standard of living; high inflation; and so on. It is a period when most macroeconomic indicators are positive. In a recession period, economic activities slow considerably. (AFDB, 2020) 


\section{Effect of Recession on SMEs Performance}

When there is short fall in household incomes as a result of economic slowdown, demand for goods and services reduces. As a result of low demand from households, firms reduce their production of such goods and services in order to cut cost. This leads to decline in profit. As production declines, workers are laid off, no buying of new equipment, no funding for research and development, no new product rollouts and general business activities also declines.

In an effort to further cut costs and improve sales, the company could compromise product quality, and in the process lose its market share.

Recession also has effect on the ability of customers to pay their debts, leading to growing non- performing loans (NPL).

\section{The Role of the Entrepreneur in Growing a business during recession}

i. Monitor inventory carefully

Usually there exists an imbalance between slumping retail sales and swollen inventories. Necessary measures should be taken to avoid leftover merchandise that tie up cash flow. The stock of slow moving products should be minimized. This way if sales nosedive, less of cash will be locked into unproductive assets.

\section{ii. $\quad$ Monitor cash flow diligently}

Ensure that expenses and planned expenditures are in line with accounts receivable. Financial statements should provide information that is timely, relevant and accurate.

iii. $\quad$ Streamline credit policy and build up capital reserves.

Watch the credit-worthiness of customers. Ensure that credit facilities are extended to trust worthy customers only. Average collection period on receivables should be reduced

iv. $\quad$ Avoid expenditures of capital nature

Consider delaying both the purchase of high cost items and expansion plans that take a long time to pay off.

v. $\quad$ Strengthen your banking relationships

Banks look for businesses to boost their income, but are also careful to minimize risk. Maintaining sound relationship with the banks might be beneficial.

vi. $\quad$ Reduce rented space where necessary

Un-used office space should be sub-letted to reduce overhead and generate additional income.

vii. Be prudently aggressive in the marketplace.

Actively seek out new business, and perhaps add a salesperson or two or an extra service to give you an edge over competition.

viii. $\quad$ Get employees involved in policy making

If layoffs or significant reduction in work hours are unavoidable, let employees take a lead role in designing the program. Shortened hours, job reassignments, job sharing and other alternatives may surface. Meet with staff regularly to exchange ideas on boosting productivity and other issues and create an incentive for good suggestions, and foster a team spirit for survival.

In a nutshell, entrepreneurs should understand that businesses go through a growth cycle and different stages should be managed using different strategies.

\section{The Role of Government in Growing a business during recession}

Broughton, (2011) stated that, governments in many countries have put in place specific policies and measures aimed at helping SMEs to survive recession. These cover a range of issues, including:

$i$ financial measures, such as reductions in tax, provision of loans, and measures to improve access to credit;

ii. helping SMEs to access new markets and to invest in research, development and innovation;

iii. providing specific advice and consultancy to SMEs, usually on themes such as how to set up operations or financial advice;

iv. $\quad$ simplification of administrative procedures, on the basis that red tape is seen as a particularly difficult barrier to business development for SMEs;

$v$. support for job creation, which usually takes the form of providing financial incentives, such as reduced employer social security contributions, for employers hiring unemployed people;

vi. enabling temporary reductions in the workforce, primarily through the provision of short-time working. This measure has been used widely throughout the EU during the recent crisis;

vii. supporting training. Training is recognized as a key instrument in ensuring employability, not just during an economic crisis, but throughout an employee's working life. SMEs often find it difficult to release employees for training and to fund training in general. Targeted measures can therefore help.

The Role of the Consumer in Sustaining SMEs during recession

Consumers have a key role to play in sustaining SMEs during recession. This is because the sustenance of the SME sector is in essence the growth of the economy that impacts positively on the lives of the citizenry. They therefore have the following roles to play. 
i. Develop a desire for patronizing local products.

ii. Consumers should develop a high sense of patriotism in settling their debts to ensure continued existence of SMEs

iii. Rather than abandoning the products of SMEs for other imported products they should suggest ways that will help SMEs to treat them better.

$i v$. Consumers are basically households who suffer decline in income during recession. It is therefore advisable that they seek alternative sources to improve their income base.

\subsubsection{Theoretical Framework}

\section{Business Growth Theories for SMEs}

There are several theories of business growth for SMEs among which are Churchill and Lewis growth Model, Gibrat's law of proportional effect, stochastic models, deterministic approach, and Greiner's Curve, just to mention a few.

For the purposes of this write-up, the researchers will focus on Greiner's Curve of six phases of business growth model. Larry E. Greiner originally proposed the Greiner Curve in 1972 with five phases of growth. Later, he added a sixth phase (Greiner, 1998).

The six growth phases are: growth through creativity, growth through direction, growth through delegation, growth through coordination and monitoring, growth through collaboration and growth through extraorganizational solutions.

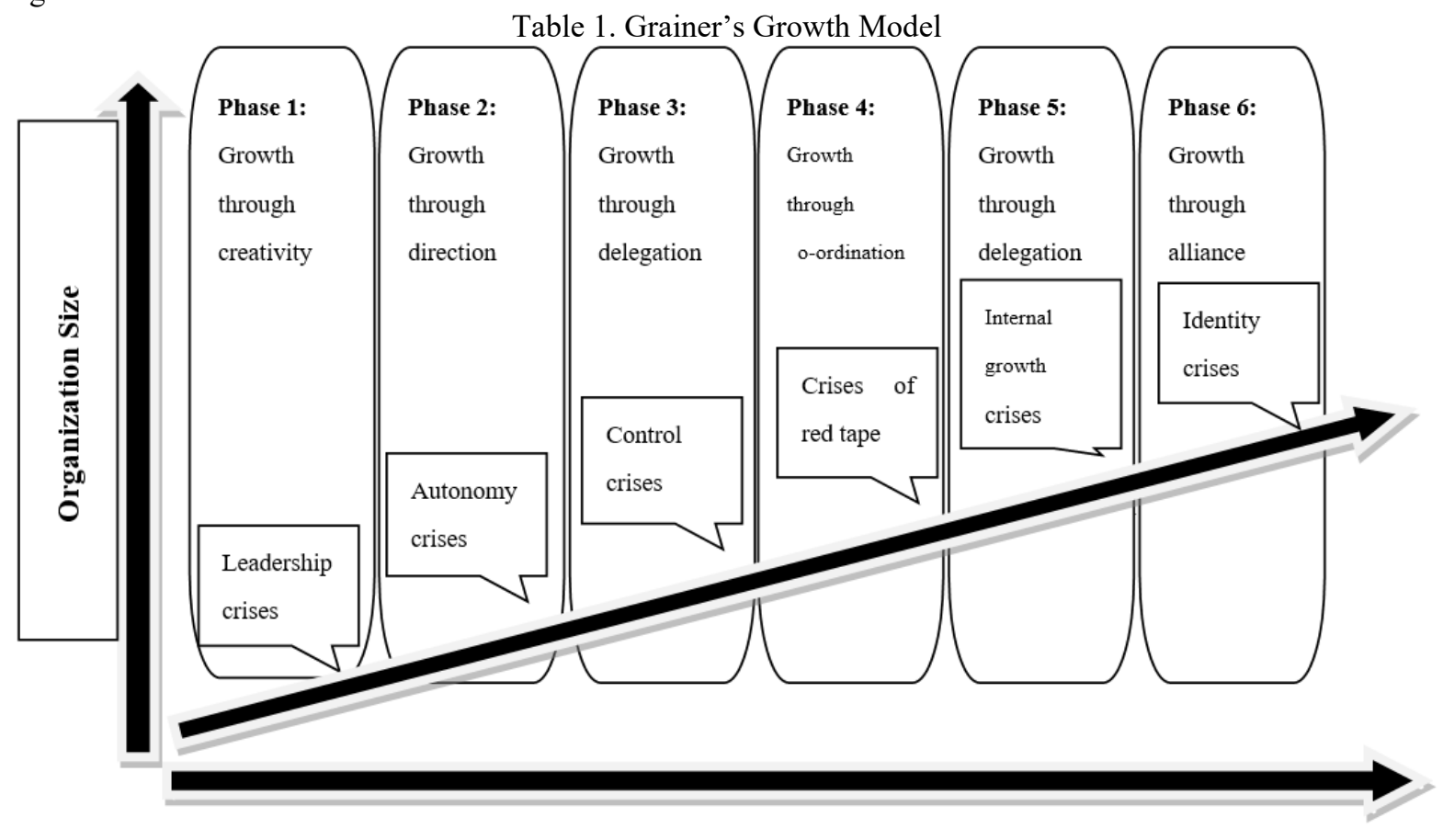

Organization age

Source: www.toolshero.com/strategy/greiner-growth-model.

Phase one: growth through creativity

This phase is characterized by the entrepreneur creating products and opening up markets. There are few staff, so informal communication works fine, However, as more staff are employed, production expands there's a need for more formal communication. This phase ends with a Leadership Crisis, where professional management is needed.

Management Strategy

Creating a business not a job - need for more dedication, monitoring and effective communication

Phase two: growth through direction

Here, growth continues in an environment of more formal communications, budgets and focus on separate activities like marketing and production. This phase ends with an Autonomy Crisis new structures based on delegation are called for.

Management Strategy

Be prudently aggressive in the marketplace - Actively seek out new business, and perhaps add a salesperson or two or an extra service to give you an edge over competition.

Phase three: Growth through delegation

This is characterized by more employees and revenue. The focus of the Entrepreneur is fostering growth through 
delegation. This phase ends with a Control Crisis.

Management Strategy

Develop an organizational chart or a corporate structure for the organization

Phase four: Growth through coordination and monitoring

An overview for this phase is that growth continues with the previously isolated business units re-organized into product groups or service practices.

This phase ends on a Red-Tape Crisis (official forms and procedures that are involved before something is accomplished).

Management Strategy

New culture and structure should be introduced.

Phase 5: Growth through collaboration

The formal controls of phases 2-4 are replaced by professionals as staff group and re-group flexibly in teams to deliver projects in a matrix structure supported by sophisticated information systems and team-based financial rewards. This phase ends with a crisis of Internal Growth.

Management Strategy

Develop partnerships with complementary organizations.

Phase 6: Growth through extra-organizational solutions (Alliance)

Greiner's recently added sixth phase suggests that growth may continue through merger, outsourcing, networks and other solutions involving other companies.

This phase ends with Identity crisis.

Management Strategy

Build a formidable transition management plan to ensure that all parties involved are satisfied with the benefit accruing from the alliance.

Other strategies for growth during recession include:

$i$. Re-examination or Assessment of Structures, policies, procedures, systems or activities, decision making, Coordination and communication networks to accommodate the economic situation.

ii. $\quad$ Formation of business clusters

iii. Internal restructuring of employee working condition.

$i v$. Understanding the market trends

$v$. Value chain management

\subsubsection{Empirical Framework}

Empirical Works carried out by researchers particularly on the topic "steering SMEs out of recession in Nigeria do not abound. What is readily available pertains to steering the Nigerian economy out of recession. Gaining general knowledge on how to steer Nigeria out of recession can be applied specifically to SMEs. A study carried out by

Hugh Mackenzie (2016) is therefore reviewed. In his work, he advocated that the strategic plans that can be employed to get an economy out of recession include: Supporting Job creation in the private sector; Investing in social and physical infrastructure, supporting skills development, fiscal capacity and so on.

Similarly, Alyssa Sharples (2011) in her research "the great recession and its effect on small businesses and unemployment rates in US" maintained that,

- $\quad$ Small business owners experience a decline in sales.

- Consumers will not be willing to buy products if they do not have jobs.

- If small businesses are struggling, they will not hire employees, which results in the unemployment rate remaining high.

- Unemployment directly affects the way small businesses operate, and the struggles of small businesses directly affect unemployment rates.

She therefore recommended that government should stimulate the economy by injecting more funds and the unemployed should become more innovative by channeling their stipends into new startups.

\subsection{Methodology}

A total number of 300 manufacturing SMEs were selected randomly from the six geopolitical zones of Nigeria in line with our definition, all having less than 300 employees and a total cost of over N50 million but not more than N200 million.

\footnotetext{
$>50$ from Benue,(in North Central),

$>50$ from Kano (in North West),

$>50$ from Taraba (in North East),

$>50$ from Lagos (in SouthWest),

$>50$ from Enugu (in South East)

$>50$ from Cross River (in South South)
} 


\subsection{Research Instrument}

In this study primary data pertaining to performance of SMEs during recession were collected. The questionnaire method was used as the principal method of data collection to elicit response. Secondary data was also used to generate statistical data on SMEs from the six geopolitical zones.

\subsection{Data Presentation and Analysis}

Regression and correlation techniques were used as analytical tools to analyze the relationship between performance of SMEs and recession. A total of 300 questionnaires were distributed out of which 270 were returned representing 90 percent.

Table 1.1 Relationship between performance of SMEs and Recession

\begin{tabular}{|l|c|c|}
\hline Response & Number of respondents & Percentage \% \\
\hline Strongly Agree & 140 & 51.85 \\
\hline Agree & 125 & 46.30 \\
\hline Disagree & 1 & 0.37 \\
\hline Strongly disagree & 0 & 0 \\
\hline Not sure & 4 & 1.48 \\
\hline TOTAL & 270 & 100 \\
\hline
\end{tabular}

Source: Field Survey 2017.

From the table above, 265 respondents representing $98.15 \%$ agreed that there is a relationship between performance of SMEs and recession. While $1.48 \%$ were not sure. This implies that there exist a relationship between the performance of SMEs and recession.

Table 1.2 The extent of the effect of recession on the performance of SMEs at different Stages of business growth.

\begin{tabular}{|l|c|c|}
\hline Response & Number of respondents & Percentage \% \\
\hline Very high & 152 & 56.30 \\
\hline High & 109 & 40.37 \\
\hline Low & 5 & 1.85 \\
\hline Very low & 4 & 1.48 \\
\hline No impact & 0 & 0 \\
\hline TOTAL & 270 & 100 \\
\hline
\end{tabular}

Source: Field Survey 2017.

From the above table, $96.67 \%$ of the respondents agreed that recession affects the performance of SMEs to a high extent while $3.33 \%$ responded that the extent of the effect is low. This implies that the extent of the effect of recession on performance of SMEs is high.

Test of Hypothesis

Using Co-relation and Regression models for analysis,

Decision Rule:

If the computed $\mathrm{t}$ - value falls within 3.182 , the null will be accepted. If it is greater, the null will be rejected accepting the alternative.

$\mathrm{H}_{\mathrm{ol}} \quad$ There exist no significant relationship between performance of SMEs and Recession Linear correlation and Regression Result

\begin{tabular}{|l|l|l|l|l|}
\hline $\mathrm{r}$ & $\mathrm{r}^{2}$ & Slope & $\begin{array}{l}\text { Y } \\
\text { Intercept }\end{array}$ & $\begin{array}{l}\text { Std. } \\
\text { Estimate }\end{array}$ \\
\hline
\end{tabular}

\begin{tabular}{|c|c|c|c|c|c|c|c|}
\hline \multicolumn{3}{|l|}{0.991} & 0.983 & & 0.876 & 6.7167 & 9.6667 \\
\hline $\mathrm{t}$ & $\mathrm{df}$ & \multirow{2}{*}{$\mathrm{P}$} & one-tailed & 0.0005 & & & \\
\hline 13.02 & 3 & & two-tailed & 0.001 & & & \\
\hline
\end{tabular}

0.95 and 0.99 Confidence Intervals of rho

Lower Limit Upper Limit




\begin{tabular}{|l|l|l|}
\hline 0.95 & 0.866 & 1 \\
\hline 0.99 & 0.706 & 1 \\
\hline
\end{tabular}

From the analysis above, the computed t-value of 13.02 at 3 degrees of freedom and using a two-tailed test at 0.05 level of significance is greater than 3.182 therefore the alternative will be accepted. Implying there exist a significant relationship between the performance of SMEs and recession.

$\mathrm{H}_{02} \quad$ Recession does not affect the performance of SMEs at different stages of business growth Linear correlation and Regression Result

\begin{tabular}{|c|c|c|c|c|c|c|}
\hline $\mathrm{r}$ & $\mathrm{r}^{2}$ & Slope & $\begin{array}{l}\mathrm{Y} \\
\text { Interc }\end{array}$ & ept & $\begin{array}{l}\text { Std. Err. of } \\
\text { Estimate }\end{array}$ & \\
\hline & & 0.992 & 0.984 & 0.89 & \begin{tabular}{l|l}
95 & 5.4757
\end{tabular} & 9.4327 \\
\hline
\end{tabular}

\begin{tabular}{|c|c|c|c|c|}
\hline $\mathrm{t}$ & $\mathrm{df}$ & \multirow{2}{*}{$\mathrm{P}$} & one-tailed & 0.0005 \\
\hline 13.566 & 3 & & two-tailed & 0.0009 \\
\hline
\end{tabular}

0.95 and 0.99 Confidence Intervals of rho

\begin{tabular}{|l|l|l|}
\hline \multicolumn{1}{|l|}{} & Lower Limit & Upper Limit \\
\hline 0.95 & 0.88 & 1 \\
\hline 0.99 & 0.734 & 1 \\
\hline
\end{tabular}

From the analysis above, the computed t-value of 13.566 at 3 degrees of freedom and using a two-tailed test at 0.05 level of significance is greater than 3.182 therefore the alternative will be accepted. Implying recession affects the performance of SMEs at different stages of business growth.

\subsection{Conclusion}

SMEs contribute to the growth of economies by increasing the GDP of such economies. Where their performance is affected by recession, it becomes necessary that the entrepreneurs understand the strategies to employ at the various stages of their businesses in steering their firms through recession. It is important that the government takes proactive measures to assist entrepreneurs in surmounting the challenges of recession.

\subsection{Recommendation}

$i$. Provision of soft loans at single digit interest rates, tax re-bates, and improvement of power supply among others by the government as a relief to entrepreneurs.

ii. Adoption of appropriate growth strategies by entrepreneurs such as re-examination of structures, processes and procedures, formation of business clusters, value chain management and so on.

iii. Increase patronage of indigenous products by consumers.

\section{References}

Alyssa, S. (2011). The Great Recession and its Effect on Small Businesses and Unemployment Rates. Retrieved from: https://www.coastal.edu/media/administration/honorsprogram/pdf.

Ariyo (2005). Ariyo, D. (2005): Small Firms are the Backbone of the Nigerian Economy. Retrieved September 2nd, 2017, from http://www.africaeconomicanalysis.org/articles/gen/smallhtm.html.

AFDB (2021). African Economic Outlook 2021. Retrieved from https://www.afdb.org/en/countries-west-africanigeria/nigeria-economic-outlook

Broughton, A (2011). SMEs and their strategies for coping with the recession Employment Studies Issue 14. Retrieved from www.employment-studies.co.uk/news/smes-and-their-strategies-coping.

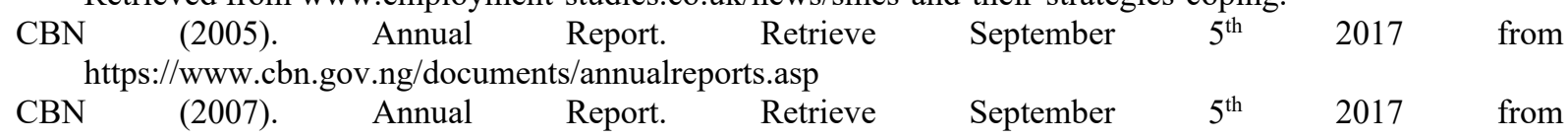
https:/www.cbn.gov.ng/documents/annualreports.asp

CBN (2012). Economic Recession. Understanding Monetary Policy Series. Vol. 14

Deen, M. H. (2003). Stake-holders Role and the Development Benefits in a virile SME sector. A Lecture paper delivered at the Manufacturing Association of Nigeria.

Etuk, R. U, Etuk, G. R and Baghebo, M 2014). Small And Medium Scale Enterprises

(SMEs) And Nigeria's Economic Development. Mediterranean Journal of Social Sciences 
Doi:10.5901/mjss.2014.v5n7p656

Greiner, (1998), The Greiner Curve:Understanding the Crises That Come With Growth. Retrieved September $5^{\text {th }} 2017$ from $h$ ttps://www.mindtools.com/pages/article/newLDR_87.htm

Mackenzie, H. (2010). Steering Ontario Out of Recession: A plan of action. A publication of Canadian Centre for Policy Alternatives.

Madza, M. A. Akpera, D. M and Ikeme A. I (2016). New Venture Creation and Growth.

National MSME Collaborative Survey (2013)

NBS Report (2016)

www.cbn.gov.ng/OUT/PUBLICATIONS/GUIDELINES/DFD/2005/SMEEIS\%20GUIDELINE.PDF

http://fsb.org.uk. 